\section{RISK OF UNINTENTIONAL INJURY IN CHILDREN WITH SENSORY IMPAIRMENT}

${ }^{1}$ Jocelyn Cherry, ${ }^{1,2}$ Julie Mytton, ${ }^{1}$ Amanda Hall, ${ }^{1}$ Cathy Williams. ${ }^{1}$ University of Bristol, UKi ${ }^{2}$ University of the West of England, UK

\subsection{6/injuryprev-2016-042156.357}

Background Unintentional injury (UI) is a leading cause of death in $<15$ s. Children have less ability to process and synthesise complex sensory information. Children with sensory impairment (SI), whether visual impairment (VI) or hearing impairment (HI), are at increased risk as they have incomplete development summated with SI.

Methods Medline (from 1950), Embase, AMED and PsychINFO were searched to Week 36, 2013. The search string was designed to maximise sensitivity. PICO was P:Children from birth to $18 \mathrm{I}$ : SI defined by the study authors as 'significant' C: Not impaired O: UI - medically attended or self-care. Exclusion criteria were papers with mixed ages with no separate children's data, varied impairments (I) with no outcomes by I, or mixed levels of I with no separate data for significant I. The systematic review was registered with PROSPERO, the International Prospective Register of Systematic Reviews.

Results 16,466 articles were title reviewed and 15,290 excluded. 1,176 abstracts were reviewed and 1,139 excluded. Grey literature searching identified a further paper. 38 full papers were reviewed with 16 articles included. 22 articles were excluded. A narrative synthesis of the heterogenous data found increased risk of UI with increasing age, male sex, being from an ethnic minority, of low socio-economic status, having low activity levels and for dental UI specifically risk was increased with overjet $>3.5$ $\mathrm{mm}$, severe malocclusion, inadequate lip coverage and poor oral health.

- No cohort studies or trials were found. No research was found covering some of the major types of childhood UI such as drowning or fire-related UI. Nor covering the effect of the severity of the impairment on UI risk. Nor covering effect of comorbidities on UI risk in SI.

Conclusions Little is currently known about the impact of SI on UIs. This review suggests SI increases a child's risk of UI. Surprising gaps in evidence were found. Further high-evidence level studies are needed.

\section{INCREASING SAFETY IN TRANSPORTATION OF CHILDREN WITH SPECIALS HEALTHCARE NEEDS: A CLOSER LOOK AT A PAEDIATRIC HOSPITAL'S APPROACH TO ADDRESSING GAPS}

\begin{abstract}
${ }^{1}$ Helen Arbogast, ${ }^{1}$ Shelby L Bachman, ${ }^{1} Y i$ Gu, ${ }^{1}$ Alejandra Arriaga, ${ }^{1,2}$ Rita V Burke, 1,2 Jeffrey S Upperman. 'Division of Paediatric Surgery, Children's Hospital Los Angeles, Los Angeles, CA, USA 90027; ${ }^{2}$ Keck School of Medicine, University of Southern California, Los Angeles, CA, USA 90089
\end{abstract}

\subsection{6/injuryprev-2016-042156.358}

Background Car seats are vital for reducing the incidence of motor vehicle-related injury and death. Many children with special healthcare needs require specialised transportation resources, which can be costly and difficult to instal. The present study aims to characterise the patient population served by a paediatric hospital's special needs car seat loaner program and communitybased special needs inspection station data. These concerted efforts attempt to improve the occupant safety children special healthcare needs.

Methods Child Passenger Safety Technicians (CPSTs) certified in special healthcare needs, conducted car seat consultations for patients over a 2-year period. In each consult, a CPST evaluated the patient and provided an appropriate loaner seat, along with education regarding proper installation of the seat. Additionally, car seat inspection station collected data on child restraint selection and installation (uses and misuses) of children with special healthcare needs in the community.

Results Car seats were distributed to 124 patients throughout the hospital. The community-based car seat inspection station provided insight on selection, installation and referral processes for children with special healthcare needs. Both strategies provided special needs CPS resources to children and increased safe transportation options for families.

Conclusions The loaner program served children with temporary and long-term special healthcare needs. The special needs inspection station provided a unique insight to selection, installation and educational resource needs related to transportation. Car seat loaner programs for special needs children offers costeffective and convenient means of promoting child passenger safety for children with a variety of unique medical needs.

\section{FACTORS INFLUENCING SAFE ACTIVE PLAY FOR CHILDREN WITH AUTISM SPECTRUM DISORDERS}

Lise Olsen, Nichole Davies, Trisha-Lee Metro. University of British Columbia, Canada

\subsection{6/injuryprev-2016-042156.359}

Background Participation in physical activity can provide important health benefits for children living with Autism Spectrum Disorders (ASD). Children with ASD, however, experience increased risk of injury along with higher levels of inactivity and obesity. The increased injury risks are related social, sensory, and behavioural factors. Parents of children with ASD also express safety concerns which may influence children's participation in activities. In light of these factors, there is a need for better understanding of the barriers and supports for children with ASD to take part in safe and active play opportunities.

Methods This project explored the views of parents and service providers about factors influencing safe and active play for children with ASD, who were 3-12 years in age and residing in the Okanagan region of British Columbia, Canada. A qualitative, ethnographic approach was used that included in-person, in-depth interviews with parents and service providers that were conducted in 2015. Data collection also included participant observation in recreation settings and review of relevant documents. Grounded theory and constant comparison was used to identify categories and major themes.

Results Parents and providers identified a range of specific child safety concerns including bolting and wandering behaviours, access to outdoor hazards, and falls and collisions during play. Barriers and supportive factors were identified at both child and family levels. At the community level, factors in the social and physical environments were seen to play key roles along with community programming and services.

Conclusions Program planning for safe recreation opportunities for children with ASD should be informed by consideration of barriers and supports at varied levels. Programs and policies that address local needs and provide secure environments can help to 
promote increased opportunities for active and safe play engagement for children with ASD.

\section{SOCIAL IMPACT ON LOWER LIMB DISABILITY AMONG URBAN COMMUNITY DWELLING RESIDENTS IN SRI LANKA}

1,2Inoka Eranganie Weerasinghe, ${ }^{3}$ Pushpa Fonseka, ${ }^{4}$ Samath Dharmaratne, ${ }^{4}$ Sumedha Jayatilake. 'Ministry of Health, Sri Lanka; ${ }^{2} J o h n s$ Hopkins Centre for Injury Research and Policy, Johns Hopkins Bloomberg School of Public Health, Johns Hopkins University, Baltimore, USA; ${ }^{3}$ University of Sri Jayawardanapura, Sri Lanka; ${ }^{4}$ University of Peradeniya, Sri Lanka

\subsection{6/injuryprev-2016-042156.360}

Background Social impact refers to changes in the ways in which people live, work, relate to one another, organise to meet their needs and their cultural norms and beliefs. Disability is often a perception created by social environment. Therefore, physically disabled people are more vulnerable and suffer more due to societal prejudices than due to health conditions. Present study explored the social impact due to limb disability in terms of attitudes among a group of city dwelling residents in Sri Lanka.

Methods A qualitative research was conducted using in-depth interviews to extract data on social impact associated with unilateral limb disability in year 2012. A sample of persons with unilateral lower limb disability $(n=12)$ were selected from a major study to assess the physical disability in a selected population in central Sri Lanka. An interviewer guide prepared on a conceptual framework was used to extract information from in-depth interviews.

Results People had different attitudes and behaviours towards the limb disabled. Participants described several enacted, perceived and internalised stigma experiences such as being criticised and isolated by the community, health providers, friends and relatives as well as denial of access to education and meaningful work roles. Some people helped and consoled the limb disabled. Some participants had feelings of discrimination by the society especially in conditions of disfigurement. Non acceptance of the social sympathy on one's disability status was demonstrated by several participants. Lack of safety and accessibility facilities confined them to their residential facilities.

Conclusions Implementation of safety and accessibility facilities, community awareness programmes and improvement of social attitudes associated with limb disability depending on the age, gender and education are necessary for Sri Lanka.

\section{Parallel Sessions Wednesday 21.9.} 8:30-10:00

\section{Rural and Agricultural Safety}

\section{Parallel Wed 1.1}

\section{A POPULATION-BASED STUDY OF ALL-TERRAIN VEHICLE EXPOSURE IN A RURAL COUNTY}

Gerene Denning, Justin Chau, Karisa Harland, Charles Jennissen. Department of Emergency Medicine, University of lowa Carver College of Medicine, USA

10.1136/injuryprev-2016-042156.361
Background All-terrain vehicle (ATV) crashes are common in agricultural communities, but few studies have reported on who is being exposed and may be at greatest injury risk. This study was performed to determine the epidemiology of ATV exposure and crashes in a rural county.

Methods Data was analysed from the Keokuk County Rural Health study which is a prospective population-based, longitudinal study of residents in Keokuk County, Iowa. Descriptive and comparative analyses were performed on 2006 Round 3 survey data which included ATV-related questions.

Results Of 1,123 respondents, 38\% reported having ridden an ATV in the previous year. Respondents who were male, younger, currently working on a farm, had higher income, or owned/ rented more acres had a greater likelihood of recent ATV exposure. Adults with children in the home were more likely to have ridden an ATV in the past year than those with none $(53 \%$ vs. $28 \%, \mathrm{p}<0.0001)$. ATV exposure also varied by place of residence, with $57 \%$ of those living on a farm being exposed vs. $20 \%$ of those living in town $(\mathrm{p}<0.0001)$. Respondents who were working on farms had the highest exposure rates $(75 \%)$. Those 12-19 years of age, with taxable household income < $\$ 60,000$, and adults who had never been married were each significantly more likely to have experienced an "ATV wreck" in the previous year. Of adults, 92\% never wore a helmet when riding an ATV with "don't own a helmet" the most common reason (43\%). Ten percent reported having been injured on an ATV in the past with more than one-half requiring medical attention. Previous safety training was reported by only $14 \%$ of adults having had ATV exposure in the past year.

Conclusions Study respondents had a high exposure to ATVs, particularly young people and those who lived or worked on farms. Safety training efforts should be focused on demographic groups identified with higher exposure and greater likelihood of ATV crash, including agricultural workers and their families.

\section{GENDER DIFFERENCES IN WORK TASKS AND INJURIES IN AGRICULTURE}

${ }^{1}$ Janne P Karttunen, ${ }^{2}$ Risto H Rautiainen. ${ }^{1} T T S$ Work Efficiency Institute, Finland; ${ }^{2}$ University of Nebraska Medical Centre, USA

\subsection{6/injuryprev-2016-042156.362}

Background Research indicates that farmers in general and livestock farmers in particular have an elevated risk of work-related adverse health outcomes. We investigated gender differences in work tasks and occupational injuries in the Finnish farming population covered by the mandatory workers' compensation insurance.

Methods Insurance claims data were augmented with data from a postal survey containing questions about the relative division of farm work between male and female farmers.

Results Over the 5-year study period (2009-2013), the average number of farmers was 73,870 (males $67 \%$ and females 33\%) with a total of 23,004 compensated occupational injuries (males $75 \%$ and females 25\%). Claims most frequently involved work tasks related to animal husbandry. Altogether 319 usable responses were received to the postal survey (12.9\% response rate). Farm work time and occupational injuries differed by gender. In general, crop production, construction work, forestry work, and few other farm work tasks including repair and maintenance of machines, and farmstead and road maintenance were male-dominated, whereas females took the main responsibility 